\title{
Lactobacillus crispatus inhibits growth of Gardnerella vaginalis and Neisseria gonorrhoeae on a porcine vaginal mucosa model
}

\author{
Laura M. Breshears ${ }^{1}$, Vonetta L. Edwards², Jacques Ravel ${ }^{2}$ and Marnie L. Peterson ${ }^{1 *}$
}

\begin{abstract}
Background: The vaginal microbiota can impact the susceptibility of women to bacterial vaginosis (BV) and sexually transmitted infections (STIS). BV is characterized by depletion of Lactobacillus spp., an overgrowth of anaerobes (often dominated by Gardnerella vaginalis) and a pH > 4.5. BV is associated with an increased risk of acquiring STIs such as chlamydia and gonorrhea. While these associations have been identified, the molecular mechanism(s) driving the risk of infections are unknown. An ex vivo porcine vaginal mucosal model (PVM) was developed to explore the mechanistic role of Lactobacillus spp. in affecting colonization by G. vaginalis and Neisseria gonorrhoeae.

Results: The data presented here demonstrate that all organisms tested can colonize and grow on PVM to clinically relevant densities. Additionally, G. vaginalis and N. gonorrhoeae form biofilms on PVM. It was observed that lactic acid, acetic acid, and hydrochloric acid inhibit the growth of G. vaginalis on PVM in a pH-dependent manner. N. gonorrhoeae grows best in the presence of lactic acid at pH 5.5, but did not grow well at this $\mathrm{pH}$ in the presence of acetic acid. Finally, a clinical Lactobacillus crispatus isolate (24-9-7) produces lactic acid and inhibits growth of both $G$. vaginalis and N. gonorrhoeae on PVM.

Conclusions: These data reveal differences in the effects of $\mathrm{pH}$, various acids and L. crispatus on the growth of $\mathrm{G}$. vaginalis and $\mathrm{N}$. gonorrhoeae on a live vaginal mucosal surface. The PVM is a useful model for studying the interactions of commensal vaginal microbes with pathogens and the mechanisms of biofilm formation on the vaginal mucosa.
\end{abstract}

Keywords: Lactobacillus, Vaginal explants, Bacterial vaginosis, Microbiota, Sexually transmitted infections, Vaginal mucosa, Biofilm

\section{Background}

Sexually transmitted infections (STIs) are a worldwide public health problem accounting for over 1 million newly acquired infections every day (World Health Organization). The two most commonly reported bacterial STIs in the United States are chlamydia (caused by Chlamydia trachomatis) and gonorrhea (caused by Neisseria gonorrhoeae) (Centers for Disease Control). If left untreated, these STIs cause significant health risks such as pelvic inflammatory disease (PID) in women,

\footnotetext{
* Correspondence: peter377@umn.edu

'Department of Experimental and Clinical Pharmacology, College of Pharmacy, University of Minnesota, 4-442 McGuire Translational Research Facility, 2001 6th St. SE, Minneapolis, MN 55455, USA

Full list of author information is available at the end of the article
}

which can lead to infertility, chronic pelvic pain and ectopic pregnancy [1]. Bacterial vaginosis (BV) is the most common vaginal condition reported by women and evidence suggests that this condition can also be sexually transmitted $[2,3]$. BV is associated with preterm birth, endometritis and increased risk of acquisition and transmission of STIs, including $C$. trachomatis, $N$. gonorrhoeae, and HIV [4-9]. While BV is a complex disorder thought to arise from the overgrowth of a wide array of anaerobes [10-12] and a decreased proportion of Lactobacillus spp. [13], Gardnerella vaginalis often predominates during BV and is thought to form a biofilm that is associated with BV recurrence $[14,15]$.

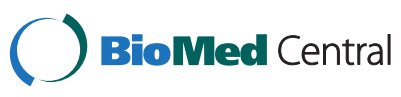

(c) 2015 Breshears et al. Open Access This article is distributed under the terms of the Creative Commons Attribution 4.0 International License (http://creativecommons.org/licenses/by/4.0/), which permits unrestricted use, distribution, and reproduction in any medium, provided you give appropriate credit to the original author(s) and the source, provide a link to the Creative Commons license, and indicate if changes were made. The Creative Commons Public Domain Dedication waiver (http://creativecommons.org/publicdomain/zero/1.0/) applies to the data made available in this article, unless otherwise stated. 
The constituents of the vaginal microbiota can affect susceptibility to STIs, though little is known about the molecular mechanisms at work in these interactions. In particular, women with Lactobacillus-dominated vaginal microbiota are at lower risk of contracting $N$. gonorrhoeae and other STIs [16-19]. Lactobacillus spp. inhibit growth of $N$. gonorrhoeae in vitro, and inhibitory strains are more prevalent in women not infected with gonorrhea [20]. Depending on growth conditions, Lactobacillus spp. inhibit $N$. gonorrhoeae and G. vaginalis, through production of hydrogen peroxide $\left(\mathrm{H}_{2} \mathrm{O}_{2}\right)$, lactic acid and/or secreted proteins [17, 21-28]. It is unlikely though that $\mathrm{H}_{2} \mathrm{O}_{2}$ plays a major role in vivo as physiological concentrations are below that required for inhibition of $\mathrm{BV}$-associated bacterial growth [26]. The majority of investigations into the interactions of Lactobacillus spp. with $N$. gonorrhoeae and G. vaginalis have been performed in vitro. While this work has provided valuable insights into these interactions, more complex models are required to expand our knowledge of how vaginal Lactobacillus spp. influence pathogen attachment, growth and virulence in the female reproductive tract.

While mouse models of both $N$. gonorrhoeae and G. vaginalis infection have been developed, these models are limited by the fact that the mouse vaginal epithelium in keratinized (unlike the squamous epithelium of the human vaginal epithelium), and that the resident mouse microbiota has been somewhat characterized and is not similar to that of humans [29]. Further, the mouse vaginal $\mathrm{pH}$, which is thought to be a critical factor in STI protection, is higher than that of humans and it is unclear how well results in mice extrapolate to humans [30-33]. Mice are also relatively expensive and low throughput. Our limited understanding of vaginal microbial interactions with one another and with host mucosa highlight the need for a new model that will allow these questions to be addressed in a biologically complex and defined environment.

Porcine vaginal mucosa (PVM) may represent a novel model for STI interactions with the resident microbiota and the host mucosal surface. PVM is an excellent model of the human vagina. As in humans, PVM is composed of a stratified, squamous epithelium with a similar surface lipid composition and underlying resident immune infiltrate [34]. PVM is also similar to the human vagina in $\mathrm{pH}$ and permeability characteristics. An ex vivo PVM model has been used extensively to study the interactions of Staphylococcus aureus and its virulence factors with the host mucosa, as well as to investigate biofilm formation and antimicrobial efficacy [35-46]. The similarity of PVM to the human vaginal mucosa, and its demonstrated use as a model for pathogen/host interactions and biofilm formation make it an excellent candidate for similar investigations with STI pathogens.
In the current study, the ex vivo PVM tissue model was used to explore the role of cervicovaginal Lactobacillus spp. in affecting colonization and growth of G. vaginalis and $N$. gonorrhoeae. It was hypothesized that human clinical isolates of Lactobacillus spp., G. vaginalis and $N$. gonorrhoeae can colonize and grow on ex vivo PVM, form biofilm (G. vaginalis and N. gonorrhoeae), and that interactions of these organisms could be investigated using the PVM model. The data presented support these hypotheses and demonstrate a clear role for $\mathrm{pH}$ and Lactobacillus in inhibition of pathogen growth on live vaginal mucosa.

\section{Results}

Human clinical isolates grow and form biofilm on PVM

The PVM is obtained as relatively large specimens $(\sim 12 \times 6 \mathrm{~cm})$, from which $5 \mathrm{~mm}$ biopsies are taken and trimmed to produce mucosal explants (Fig. 1a) [37]. To determine if human clinical bacterial isolates can grow on PVM, explants were inoculated with $\sim 10^{4} \mathrm{CFU} /$ explant of Lactobacillus spp., G. vaginalis, and N. gonorrhoeae. L. crispatus consistently grew 2 to 3 logs, exhibiting peak growth at $48 \mathrm{~h}$ post-inoculation with $\sim 2.6 \times 10^{6} \mathrm{CFU} /$ explant $\left(\sim 1.0 \times 10^{7} \mathrm{CFU} / \mathrm{ml}\right)$ (Fig. 1b). L. iners, L. jensenii, and $L$. gasseri also showed maximal growth at $48-72 \mathrm{~h}$ with $\sim 10^{7} \mathrm{CFU} /$ explant, but they were not used for further experiments in the current study (data not shown). G. vaginalis grew to $\sim 3.4 \times 10^{7} \mathrm{CFU} /$ explant $\left(\sim 1.3 \times 10^{8} \mathrm{CFU} / \mathrm{ml}\right)$ with peak growth at $48-72 \mathrm{~h}$ (Fig. 1c). N. gonorrhoeae grew to $\sim 1.1 \times 10^{7} \mathrm{CFU} /$ explant $\left(\sim 4.2 \times 10^{7} \mathrm{CFU} / \mathrm{ml}\right)$ with peak growth at $24-48 \mathrm{~h}$ (Fig. 1d). It should be noted that $N$. gonorrhoeae grew best on the PVM when the underlying media was at pH $5.5-6.5$ (see below). All N. gonorrhoeae experiments were performed under aerobic conditions, as $N$. gonorrhoeae did not grow on PVM anaerobically with RPMI as the underlying media. All other organisms were grown on PVM anaerobically.

$N$. gonorrhoeae can form a biofilm in continuous-flow chambers and on human cervical epithelial cells, suggesting that biofilm formation in vivo may play a role in pathogenesis [47, 48]. Similarly, G. vaginalis can form a biofilm in vitro and in vivo that might contribute to the resistance of BV to standard treatments [49-52]. The ability of N. gonorrhoeae and G. vaginalis to form biofilm on PVM was assessed in order to determine if the PVM model can be used to study the mechanisms of biofilm formation. A LIVE/DEAD stain was used with confocal microscopy to visualize both biofilm development and the health of PVM epithelium. By 24 h post-inoculation, single and microcolonies of adherent bacteria were observed on PVM explants colonized with G. vaginalis (Fig. 2e). Where these colonies were observed, the underlying epithelium showed a mix of live (green) and dead (red) cells, whereas on areas of tissue that did not show bacterial colonization, the epithelium appeared mostly green as in 
A

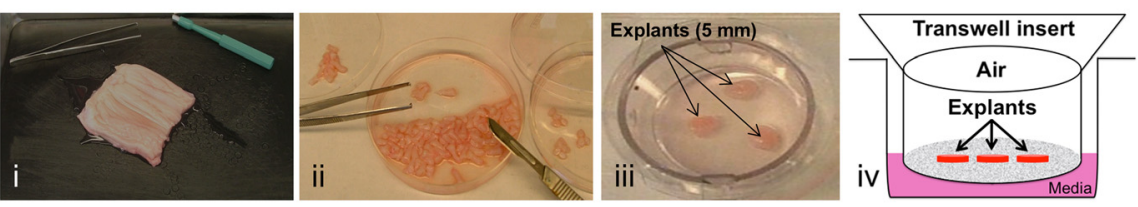

B

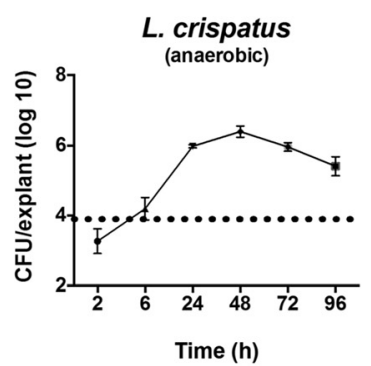

C

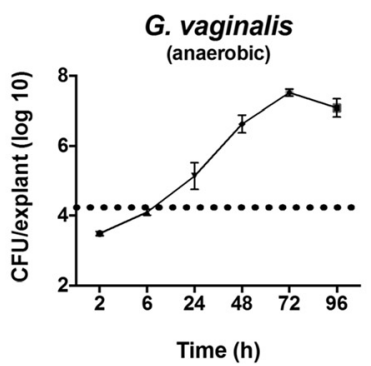

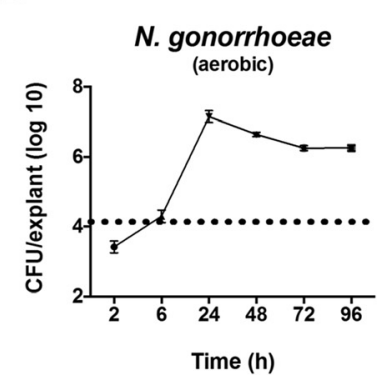

Fig. 1 Growth of human clinical isolates on porcine vaginal mucosa (PVM). a PVM is obtained as large specimens (i) and 5 mm explants are trimmed (ii) and placed mucosal side up in transwells over liquid media (iii, iv). "Air" refers to either an aerobic or anaerobic environment depending on the experiment being performed. b L. crispatus, c G. vaginalis, and d N. gonorrhoeae were inoculated onto PVM explants at $\sim 10^{4}$ CFU/explant (dotted lines). Explants were processed for CFU/explant at each time point to evaluate bacterial growth. Data was log ${ }_{10}$ transformed and plotted on a log scale as the mean $\pm S D$

the uninfected controls (Fig. 2a). By 48 h, patchy G. vaginalis biofilm was observed that thickened and colonized more of the surface area of the tissue over time (Fig. 2f-h). For these large areas of biofilm the underlying epithelium was either completely degraded or composed of dead cells (red). PVM colonized with $N$. gonorrhoeae exhibited robust biofilm development within $24 \mathrm{~h}$ (Fig. $2 \mathrm{~m}$ ) when compared to uninfected controls (Fig. 2i). By $48 \mathrm{~h}$ postinoculation, $N$. gonorrhoeae formed a thick biofilm covering most of the surface of the explants (Fig. 2n-p). Control tissue remained healthy and uninfected over the course of the experiment (Fig. 2i-l). Unlike the epithelial toxicity observed with $G$. vaginalis biofilm, epithelial cells that could be seen between patches of $N$. gonorrhoeae biofilm were mostly green indicating that they were alive. Biofilm was not observed on explants colonized with $L$. crispatus alone at any time-point (data not shown).

\section{Low $\mathrm{pH}$ inhibits growth of $G$. vaginalis and $N$. gonorrhoeae on PVM}

Lactic acid is thought to play a critical and complex role in maintaining a healthy vaginal environment [23]. It is thought that one important function of lactic acid is inhibiting the growth of potentially pathogenic organisms including G. vaginalis and N. gonorrhoeae. Acetic acid is produced by G. vaginalis and other anaerobes and high levels of acetic acid in vaginal fluid are associated with BV [53-56]. To determine if lactic acid, acetic acid or acidity alone (using $\mathrm{HCl}$ ) affect growth of the organisms under study on the PVM model, culture media containing acids at $\mathrm{pH} 7.0,5.5$ or 4.0 were produced and placed under transwell membranes containing explants prior to inoculation with various organisms. A reduction in $\mathrm{pH}$ with any of the three acids tested had no affect on growth of $L$. crispatus at $48 \mathrm{~h}$ post-inoculation (Fig. 3a). In contrast, G. vaginalis and $N$. gonorrhoeae were unable to grow on PVM in the presence of media adjusted to $\mathrm{pH} 4.0$ with all three acids tested (Fig. 3b, c). Interestingly, while N. gonorrhoeae grew well over both lactic acid and $\mathrm{HCl}$ at $\mathrm{pH} 5.5$, it consistently grew poorly over acetic acid at $\mathrm{pH} 5.5$, regardless of inoculum.

\section{L. crispatus produces lactic acid and inhibits growth of $G$.} vaginalis and $N$. gonorrhoeae on PVM

Lactobacillus spp. inhibit in vitro growth of G. vaginalis and $N$. gonorrhoeae $[20,27,57]$. Co-colonization experiments were performed to determine if $L$. crispatus affects G. vaginalis and N. gonorrhoeae growth on PVM. Because inhibition of growth of G. vaginalis and $N$. gonorrhoeae is thought to rely in part on lactic acid production by vaginal Lactobacillus spp., resulting in low $\mathrm{pH}$, unbuffered RPMI was initially used to maintain explants. PVM was inoculated with L. crispatus for $48 \mathrm{~h}$ prior to addition of G. vaginalis (all incubations were performed under anaerobic conditions). Under these conditions, the $\mathrm{pH}$ of the media under the transwells containing explants inoculated with L. crispatus did not go below 6.0 (Fig. 4a) and growth of G. vaginalis was only reduced by $\sim 1 / 2 \log$ (Fig. $4 b$ ).

It seemed likely that the relatively small number of bacteria on each explant was insufficient to produce enough lactic acid to lower the $\mathrm{pH}$ of the $1 \mathrm{ml}$ of media below the transwells to $<6.0$. It was hypothesized that 

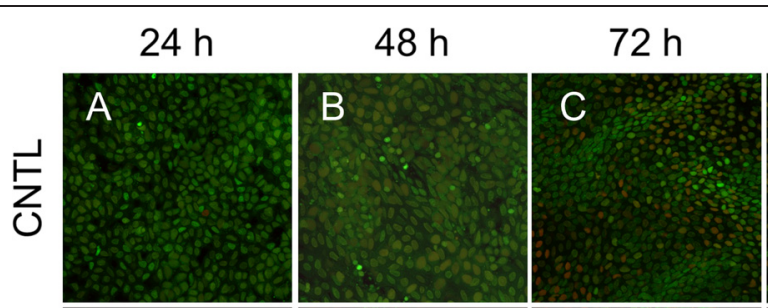

$96 \mathrm{~h}$
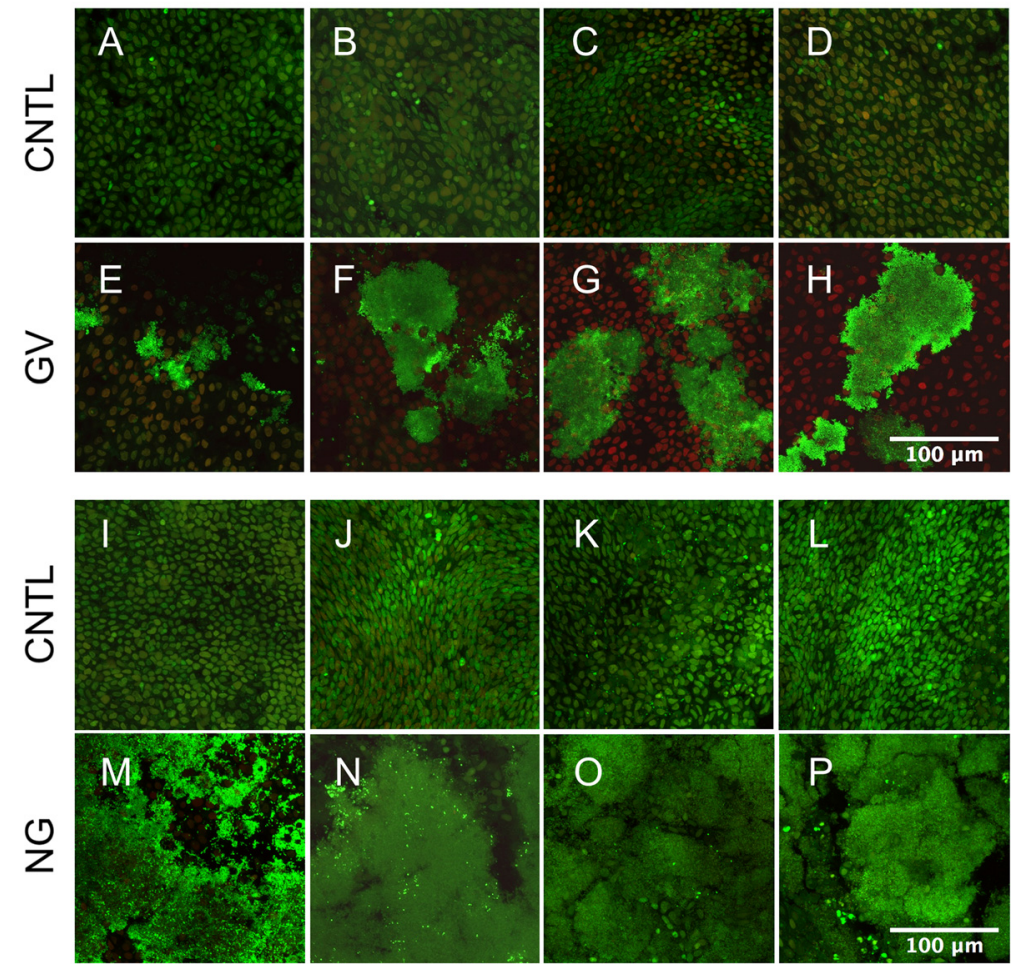

Fig. 2 G. vaginalis and N. gonorrhoeae form biofilm on PVM. Strains were inoculated onto PVM explants at 10 $0^{4}$ CFU/explant and processed for microscopy at indicated times. The LIVE/DEAD stain allows for imaging of both the mucosal epithelium and bacteria. Green cells are alive while red cells are dead. a-d, $\mathbf{i}-\mathbf{I}$ Uncolonized control (CNTL) tissue remains healthy throughout both experiments as evidenced by large green intact epithelial cells. e-h By $48 \mathrm{~h}$ post-colonization, G. vaginalis (GV) forms a patchy biofilm that persists and spreads over time (anaerobic growth). $\mathbf{m}-\mathbf{p}$ In just 24 h N . gonorrhoeae (NG) forms a robust biofilm, which thickens and persists over time (aerobic growth). Epithelial cells that can be seen under and around the NG biofilm are alive as evidenced by their green staining, while those on GV-colonized explants are dead (large red cells under the green biofilm). Scale bars $=100 \mu \mathrm{m}$ for all images

use of media previously "conditioned" by L. crispatus would support meaningful $\mathrm{pH}$ changes in the presence of $L$. crispatus. To test this hypothesis, L. crispatus conditioned media $(\mathrm{CM})$ produced by sterile filtering overnight aerobic cultures (produced without shaking) of $L$. crispatus ( $\mathrm{pH} 4.0$ - 4.5) was mixed with unbuffered RPMI resulting in a pH of $5.5-6.0$, which is permissible for growth of G. vaginalis (Fig. 3). This allowed for testing the ability of $L$. crispatus on PVM to lower the local $\mathrm{pH}$ to that observed in the vagina of healthy human subjects $(\sim \mathrm{pH} 3.5-4.5)$ and inhibit growth of G. vaginalis.

After $48 \mathrm{~h}, L$. crispatus lowered the $\mathrm{pH}$ of CM below the transwells to 4.0 , a pH that was maintained over the course of the experiments (Fig. 5a). The CM below transwells containing uninfected explants or those colonized with G. vaginalis alone remained at $\mathrm{pH} 5.0-5.5$. When G. vaginalis was added to explants pre-inoculated with $L$. crispatus, it failed to grow whereas $G$. vaginalis placed on explants alone (over $\mathrm{CM}, \mathrm{pH}$ 5.5) grew to normal densities (Fig. 5b). The levels of D- and L-lactic acid were significantly increased in CM under transwells containing explants inoculated with $L$. crispatus but not those that were uninfected or colonized with G. vaginalis alone (Fig. 5c, d). D-lactate levels produced by L. crispatus alone averaged $35.52 \pm 10.55 \mathrm{mM}$ and L-lactic acid levels averaged $19.90 \pm 2.22 \mathrm{mM}$ over 5 experiments (Fig. 5e). These data are in excellent agreement with results showing that $60 \mathrm{mM}$ lactic acid $(\mathrm{D}+\mathrm{L})$ was required to lower the $\mathrm{pH}$ to 4.0 and inhibit growth of $G$. vaginalis (Fig. $3 \mathrm{~b}$ ). It should be noted that the levels of D- and L-lactic acid reported in the "CM" columns of Fig. $5 \mathrm{c}$ and $\mathrm{d}$ are from overnight aerobic broth culture (obtained without shaking). Further accumulation of Dand L-lactic acid in this media (reported in Fig. 5c-e) was achieved under anaerobic conditions on PVM.

To directly analyze the effect of $L$. crispatus on $N$. gonorrhoeae growth, experiments were performed with unbuffered RPMI that was adjusted to pH 5.5 with lactic acid prior to inoculation. After $48 \mathrm{~h}$, L. crispatus lowered the $\mathrm{pH}$ of media below transwells to 5.0 and further lowered the $\mathrm{pH}$ to 4.5 by $96 \mathrm{~h}$ (Fig. 6a). When N. gonorrhoeae was added to explants pre-inoculated with $L$. 


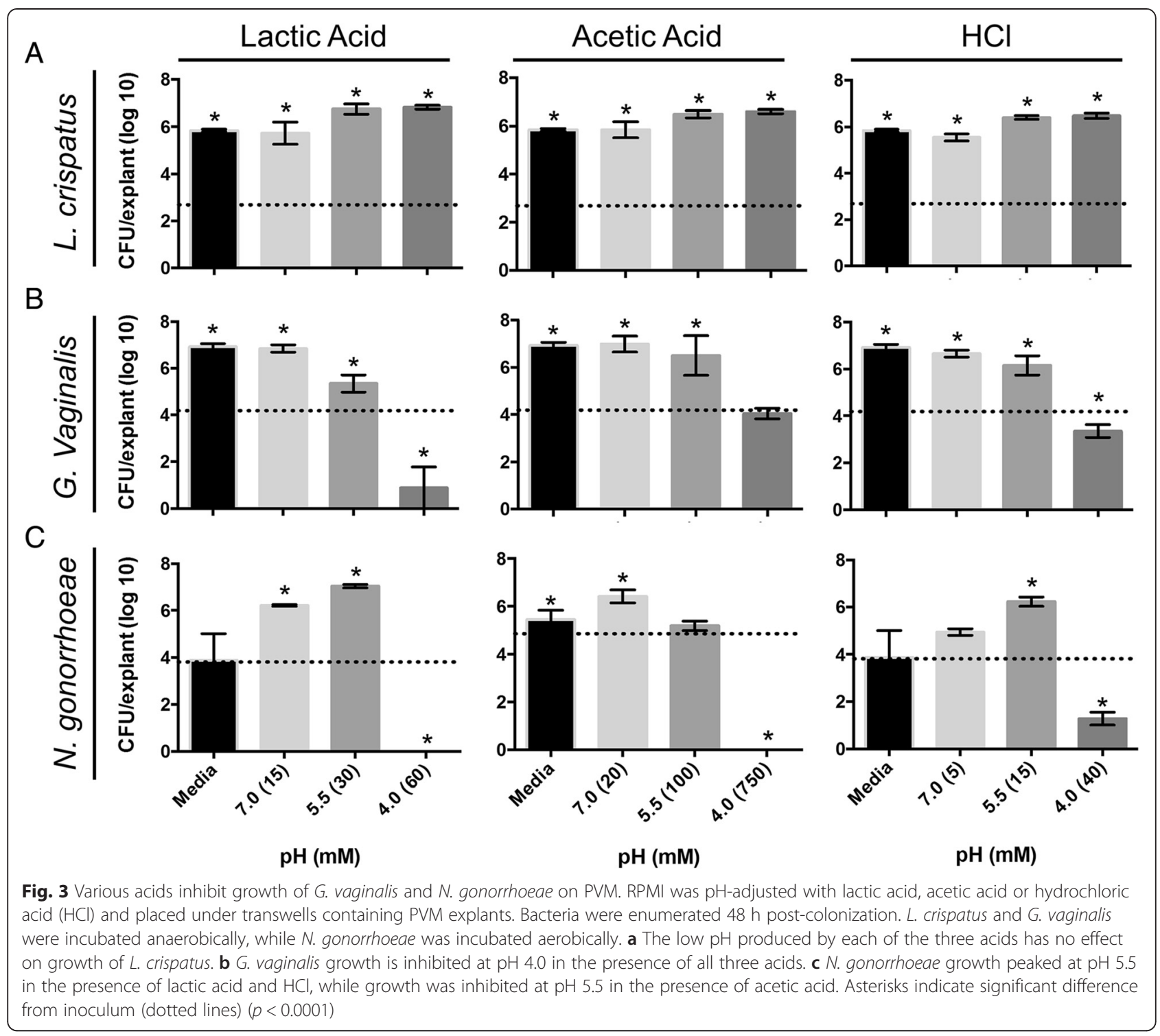

crispatus, the organism failed to grow whereas $N$. gonorrhoeae placed on explants alone grew to normal levels (Fig. 6b). The effect of L. crispatus CM on $N$. gonorrhoeae growth was also determined. After 48 h L. crispatus lowered the $\mathrm{pH}$ of underlying $\mathrm{CM}$ to 4.5 and further to $\mathrm{pH} 4.0$ after $96 \mathrm{~h}$ (Fig. 6c). The CM below transwells containing uninfected explants or those colonized with $N$. gonorrhoeae alone remained at $\mathrm{pH}$ 5.5. Surprisingly, $N$. gonorrhoeae did not survive over $\mathrm{CM}$, even at an otherwise permissible growth $\mathrm{pH}$ (5.5) and in the absence of $L$. crispatus pre-inoculation (CFUs were zero for $N$. gonorrhoeae alone over CM or with L. crispatus over CM). The inability of $N$. gonorrhoeae to survive on PVM in the presence of CM was observed with CM produced from anaerobic and aerobic L. crispatus cultures obtained without shaking (Fig. 6d). Though the background media for CM (NYC+RPMI) did affect $N$. gonorrhoeae growth on PVM, it was not bactericidal as was observed with CM. These data indicate that L. crispatus 24-9-7 produces a factor in broth culture that kills $N$. gonorrhoeae even when the $\mathrm{pH}$ is permissible for $N$. gonorrhoeae growth.

\section{Discussion}

Our limited understanding of the interactions of microbes and the importance of microbial structures such as biofilms in affecting the health of the human female reproductive system requires the development of predictive, biologically complex models. The goal of the current study was to use ex vivo PVM to model interactions of Lactobacillus with $G$. vaginalis and $N$. gonorrhoeae. Lactobacillus spp., and G. vaginalis colonize the human vagina, while $N$. gonorrhoeae is an obligate human pathogen that preferentially infects both the endo- and ectocervix [58-61]. The PVM is 


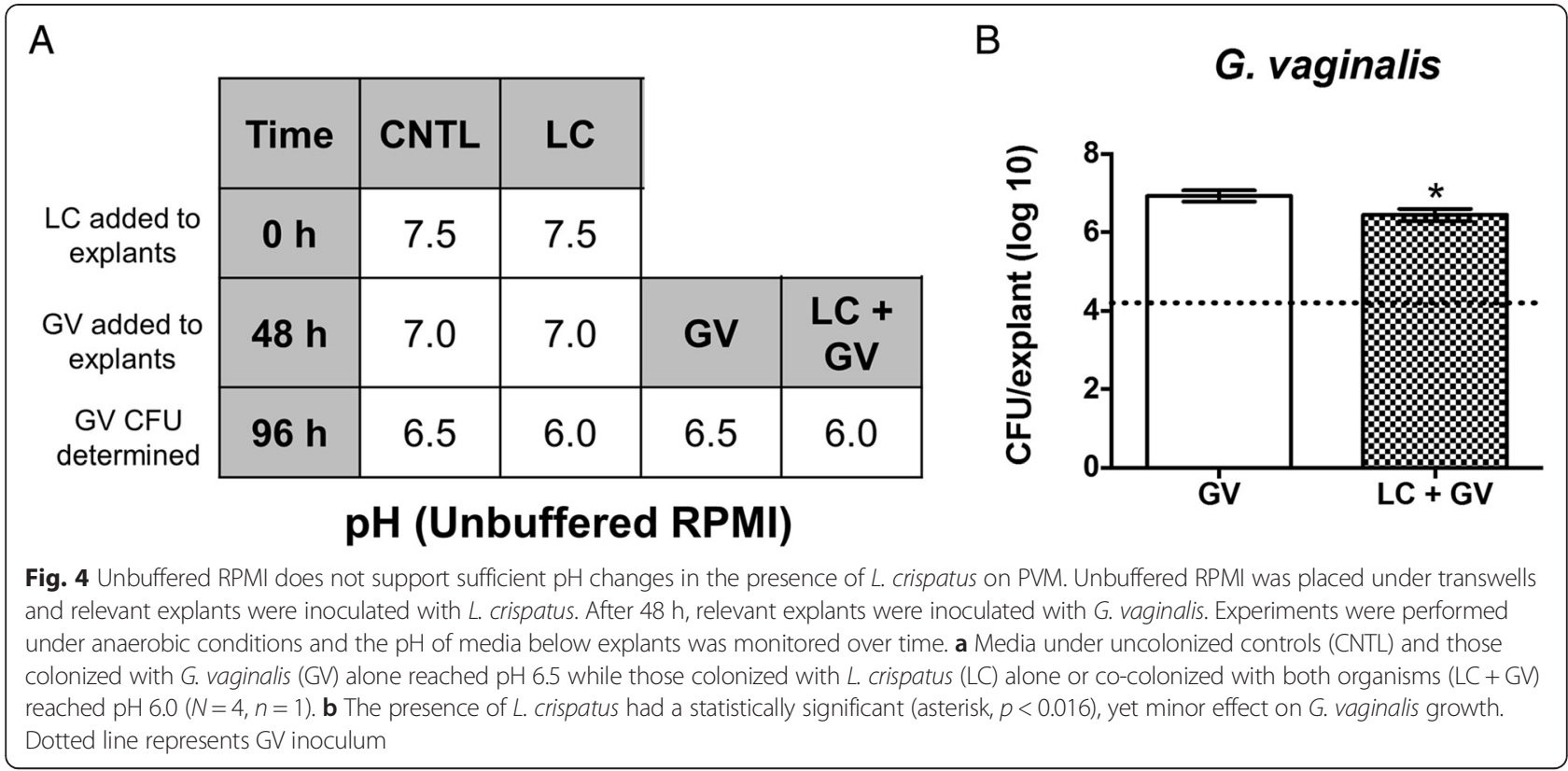

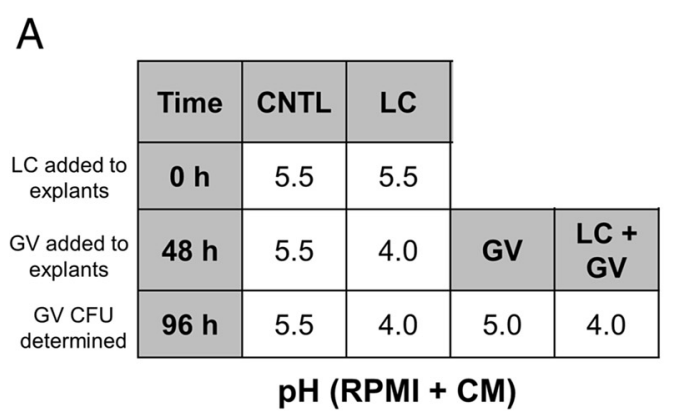

C

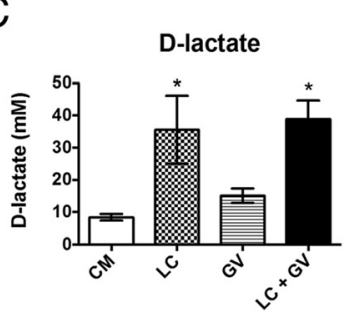

B

\section{G. vaginalis}

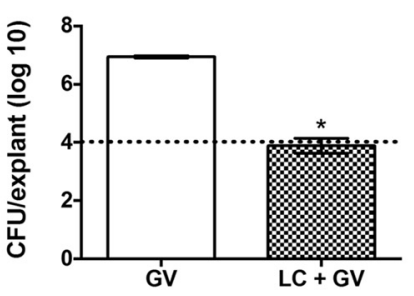

D

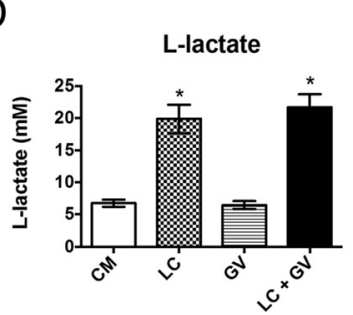

E

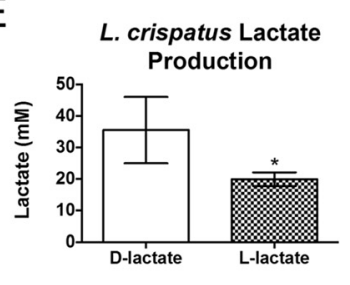

Fig. 5 Conditioned media supports L. crispatus-induced pH changes, inhibiting growth of G. vaginalis on PVM. Media from overnight aerobic broth culture of L. crispatus was sterile filtered and mixed with unbuffered RPMI to achieve pH 5.5. This conditioned media (CM) was placed under transwells and relevant explants were inoculated with L. crispatus. After $48 \mathrm{~h}$, relevant explants were inoculated with $\mathrm{G}$. vaginalis. Experiments were performed under anaerobic conditions and the $\mathrm{pH}$ of media below explants was monitored over time. a Media under uncolonized controls (CNTL) and those colonized with G. vaginalis (GV) alone remained at pH 5.0 - 5.5 while those colonized with L. crispatus (LC) alone or co-colonized with both organisms $(\mathrm{LC}+\mathrm{GV}$ ) were reduced to $\mathrm{pH} 4.0(N=6, n=1)$. b The presence of $L$. crispatus inhibited $G$. vaginalis growth. Dotted line represents $G V$ inoculum. Asterisk indicates significant difference in growth between the two groups shown $(p<0.0001)$. $\mathbf{c}$, $\mathbf{d} \mathrm{D}$ - and L-lactate levels in the CM below transwells from experiment (a) were analyzed at $96 \mathrm{~h}$. CM below explants colonized with L. crispatus (LC and LC + GV) showed a significant increase in lactic acid when compared with uncolonized controls (CM) and G. vaginalis (GV) alone $(p<0.0001)$. e A comparison of $\mathrm{D}$ - and $\mathrm{L}-$ lactate levels in $C M$ below LC alone infections shows that D-lactate is produced at $\sim 2 X$ the level of L-lactate $(p<0.002)$. (C-E) Data shown are combined $(N=5, n=1)$ 
A

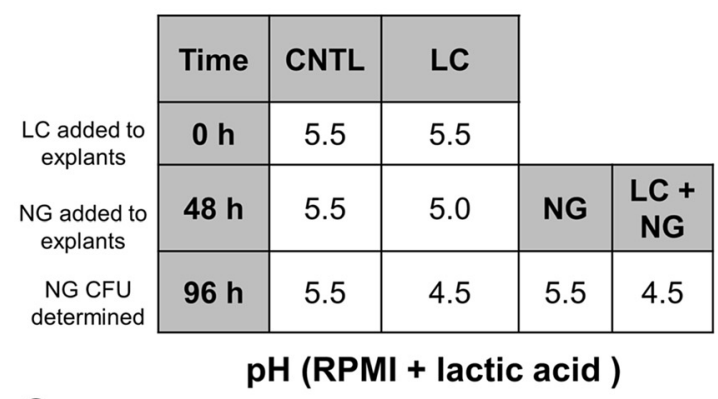

C

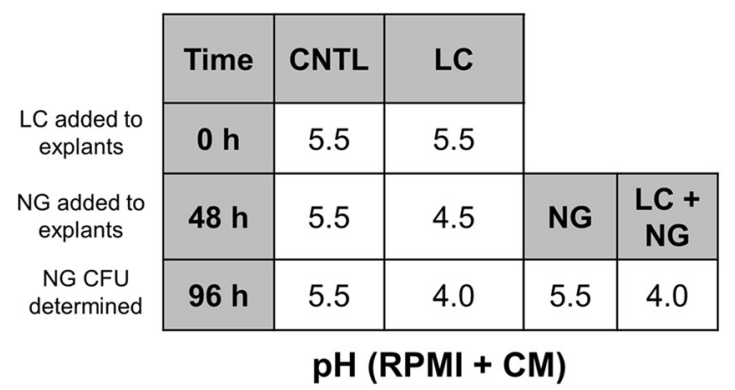

B N. gonorrhoeae

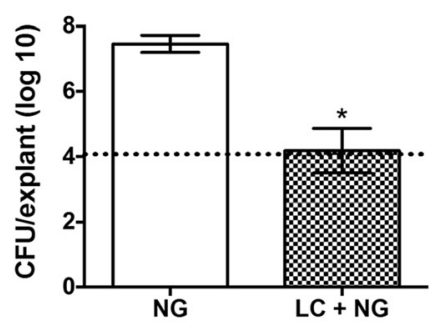

D

N. gonorrhoeae (pH 5.5)

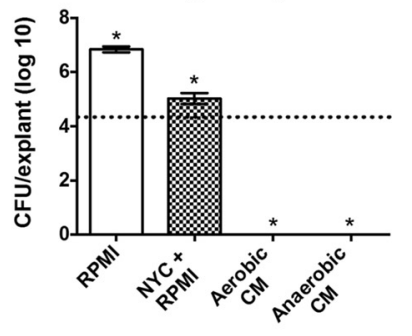

Fig. 6 L. crispatus inhibits growth of N. gonorrhoeae. a, b Unbuffered RPMI or (c) L. crispatus CM was adjusted to pH 5.5 and placed under transwells. Relevant explants were inoculated with L. crispatus. After 48 h, relevant explants were inoculated with N. gonorrhoeae. Experiments were performed under aerobic conditions and the $\mathrm{pH}$ of media below explants was monitored over time. a RPMI under uncolonized controls (CNTL) and those colonized with N. gonorrhoeae (NG) alone remained at pH 5.5 while RPMl under explants colonized with L. crispatus (LC) alone or co-colonized with both organisms $(\mathrm{LC}+\mathrm{NG})$ was reduced to $\mathrm{pH} 4.5(\mathrm{~N}=4, n=1)$. b The presence of $L$. crispatus inhibited $48 \mathrm{~h} N$. gonorrhoeae growth. Asterisk indicates significant difference in growth between the two groups shown $(p<0.002)$. c CM under CNTL or NG remains at pH 5.5 while CM under explants colonized with LC alone or co-colonized with both organisms ( $L C+N G)$ was reduced to $\mathrm{pH} 4.0(N=3, n=1)$. d While $N$. gonorrhoeae did exhibit a growth defect over NYC + RPMI media (the background media for CM) it was completely killed by aerobic or anaerobic $\mathrm{CM}$ at pH 5.5, even in the absence of a L. crispatus co-infection. Asterisks indicate significant difference from inoculum $(p<0.0001)$. For (b) and (d), dotted lines represent NG inocula

squamous epithelium similar to human vaginal and ectocervical epithelia making it an ideal candidate for ex vivo studies of these organisms. Human clinical isolates of Lactobacillus spp., G. vaginalis, and N. gonorrhoeae, colonized and grew on PVM to clinically relevant densities. Lactobacillus spp. grew to $\sim 1.0 \times 10^{7} \mathrm{CFU} / \mathrm{ml}$, which is in accordance with published findings of $10^{3}-10^{9} \mathrm{CFU} / \mathrm{ml}$ in vaginal specimens $[62,63]$. Growth of G. vaginalis on PVM $\left(\sim 1.3 \times 10^{8} \mathrm{CFU} / \mathrm{ml}\right)$ mimics the densities found during $\mathrm{BV}$, as women without $\mathrm{BV}$ are colonized by $<2 \times 10^{7} \mathrm{CFU} / \mathrm{ml}$, while those with BV are colonized by $>2 \times 10^{7} \mathrm{CFU} / \mathrm{ml}$ [64]. $N$. gonorrhoeae grew to $\sim 4.2 \times 10^{7} \mathrm{CFU} / \mathrm{ml}$, which is slightly higher than the reported range of $5 \times 10^{3}-8 \times$ $10^{6} \mathrm{CFU} / \mathrm{ml}$ obtained from vaginal washes [65]. These data demonstrate that the observed growth of human clinical bacterial isolates on PVM reflects the number of organisms found in human vaginal fluids/washes. Investigations of temporal dynamics on PVM are limited though as growth of the organisms under study generally peaked at $48-72 \mathrm{~h}$ post-colonization and waned at later time points, likely due to depletion of nutrients in this closed system.
Both G. vaginalis and N. gonorrhoeae form robust biofilms on PVM. Multiple lines of evidence suggest that biofilm formation by G. vaginalis strains in vivo is a critical first step in the development and recurrence of BV [66, 67]. Additionally, evidence suggests that the ability of any particular strain to form a biofilm may be a key factor in distinguishing pathogenic G. vaginalis from commensal strains found in many asymptomatic women [68]. The G. vaginalis strain used in this study (ATCC 14018) produces a cholesterol-dependent cytolysin (CDC), vaginolysin (VLY) $[69,70]$ that lyses cervical epithelial cells [71]. PVM colonized with G. vaginalis biofilm showed extensive epithelial cell death, suggesting that VLY might be active in this system. The Staphylococcus aureus cytolysin $\alpha$-toxin is required for biofilm formation on PVM [36] while the Streptococcus pneumoniae CDC, pneumolysin, is not required for biofilm formation in a mouse nasopharyngeal colonization model [72]. It will be interesting to determine if VLY is required for biofilm formation ex vivo and what role lysis versus epithelial cell signaling may play in the VLY 
contribution to G. vaginalis colonization and/or biofilm formation [69]. Because G. vaginalis is a genomically diverse species, other factors might be important in determining characteristics necessary for pathogenicity [73]. Future experiments will explore the molecular mechanisms used by G. vaginalis, and N. gonorrhoeae to form biofilm on PVM and the ability of Lactobacillus spp. and their secreted products to prevent/disrupt these biofilms.

Vaginal $\mathrm{pH}$ increases in women with BV and may be associated with STI susceptibility. It is becoming evident that lactic acid produced by Lactobacillus spp. contributes to overall vaginal health and inhibition of growth of pathogenic organisms in vitro [21, 23, 74]. BV-associated organisms, including G. vaginalis, produce acetic acid and there is a loss of lactic acid production and an increase in acetic acid in the vaginal fluid of women with BV $[53,56]$. Of the three acids tested, lactic acid consistently showed a much larger degree of killing $G$. vaginalis at $\mathrm{pH}$ 4.0. It may be that lactic acid has a specific bactericidal affect on G. vaginalis but it is unclear if this affect is necessary to keep G. vaginalis growth in check, or if the effects of low $\mathrm{pH}$ alone are sufficient to do so.

Co-colonization experiments with L. crispatus and G. vaginalis on PVM (anaerobic) clearly showed an association between lactic acid production, a reduction in the local $\mathrm{pH}$, and inhibition of G. vaginalis growth. These results reflect previous observations that under anaerobic conditions (where $\mathrm{H}_{2} \mathrm{O}_{2}$ is minimally produced), lactic acid inhibits growth of G. vaginalis (and other BVassociated organisms) in vitro [26]. The results here show that L. crispatus inhibition of G. vaginalis growth is $\mathrm{pH}$-dependent; lactic acid production is not sufficient to inhibit G. vaginalis growth if it is not accompanied by a reduction in $\mathrm{pH}$. L. crispatus produced higher levels of D- versus L-lactate, as previously reported for the species [75]. The differential production of D- and L-lactate by various Lactobacillus spp. may be important in influencing host responses and susceptibility to BV and future work will tease out these differences by expanding the species and strains used in co-infection experiments.

Women with Lactobacillus-dominated vaginal microbiota are less susceptible to $N$. gonorrhoeae infection $[16,19,20]$. The mechanism of inhibition of $N$. gonorrhoeae by Lactobacillus spp. is unclear as multiple studies demonstrate that lactic acid, $\mathrm{H}_{2} \mathrm{O}_{2}$, and Lactobacillus bacteriocins can inhibit $N$. gonorrhoeae growth in vitro depending on the growth conditions. Though lactic acid alone at pH 5.5 was permissible for $N$. gonorrhoeae growth, $L$. crispatus anaerobic $\mathrm{CM}$ at $\mathrm{pH} 5.5$ was not, indicating that this L. crispatus strain produces a factor other than lactic acid that inhibits $N$. gonorrhoeae growth. This data also supports the hypothesis that $\mathrm{H}_{2} \mathrm{O}_{2}$ does not likely play an inhibitory role in vivo, as $\mathrm{H}_{2} \mathrm{O}_{2}$ is undetectable in Lactobacillus broth culture incubated anaerobically and in cervicovaginal fluid $[25,76]$.

PVM represents a biologically relevant model that cannot only be used to ask fundamental questions about microbial interactions, but also help translate new technologies to clinical use. While it is likely that some host/ bacterial interactions are not identical between the porcine and human mucosal epithelia, PVM has proven to be useful in assessing host toxicity of potential antimicrobials and is predictive of clinical efficacy [38, 77]. The use of probiotic Lactobacillus spp. has been investigated as a prevention of and treatment for BV [78]. The PVM model used in this study could be used to screen potential probiotic organisms for their ability to prevent the growth of a variety of $\mathrm{BV}$-associated organisms and decipher the mechanisms of inhibition. Advantages of PVM include that it is not subject to regulation as live animal models are, it is inexpensive, relatively easy to obtain and semi-high throughput. This model is potentially an excellent platform for initial testing of novel therapeutics against STIs, such as drug-resistant strains of $N$. gonorrhoeae. Importantly, toxic effects of new drugs on the host mucosa and resident protective microbes such as Lactobacillus spp. could also be investigated with the PVM model.

Future work will include investigations of the mechanisms of biofilm formation, Lactobacillus spp. interactions with BV-associated organisms and STI agents, the host response to colonization and the efficacy of antimicrobials against STIs using the PVM model.

\section{Conclusions}

An acidic environment $(\mathrm{pH}<4.5)$ inhibits colonization of live vaginal mucosa by both $G$. vaginalis and $N$. gonorrhoeae regardless of the acid tested. $N$. gonorrhoeae grows best in the presence of lactic acid at $\mathrm{pH} 5.5$ perhaps contributing to increased susceptibility during BV. Additionally, a high concentration of acetic acid inhibits $N$. gonorrhoeae growth on PVM at $\mathrm{pH}$ 5.5. A stable $L$. crispatus colonization of live vaginal mucosa is able to prevent colonization of $G$. vaginalis in a $\mathrm{pH}$-dependent manner, while $L$. crispatus secretes a factor that kills $N$. gonorrhoeae. The PVM model will continue to be used to investigate these interactions and the mechanisms of $G$. vaginalis and $N$. gonorrhoeae biofilm formation on live vaginal tissue.

\section{Methods}

\section{Bacterial isolates and culture conditions}

$L$. crispatus, L. jensenii, L. gasseri and $L$. iners were isolated from vaginal swabs of reproductive age, asymptomatic women who were not menstruating at the time of collection. These isolates were collected as part of broader longitudinal genomic studies of the vaginal 
microbiome $[79,80]$. The clinical study protocols were approved by the Institutional Review Boards of the Johns Hopkins University School of Medicine, the University of Maryland School of Medicine and the University of Alabama at Birmingham. Written informed consent was obtained from all participants. The L. crispatus isolate used in the current study was designated 24-9-7 and was isolated from a woman who was dominated with $L$. crispatus each day of the 10-week sampling period except during menses when the community shifted and $L$. iners was dominant. $G$. vaginalis is a clinical isolate obtained from ATCC (14018). G. vaginalis and Lactobacillus spp. were cultured in New York City III (NYC III) media (10 g/L proteose peptone, $10 \mathrm{~g} / \mathrm{l}$ beef extract, $5 \mathrm{~g} / \mathrm{l}$ yeast extract, $5 \mathrm{~g} / \mathrm{L} \mathrm{NaCl}, 1.2 \mathrm{~g} / \mathrm{L}$ $\mathrm{MgSO}_{4}, 2 \mathrm{~g} / \mathrm{L} \mathrm{MnSO}{ }_{4} \cdot \mathrm{H}_{2} \mathrm{O}, 5.7 \mathrm{~g} / \mathrm{L} \mathrm{K}_{2} \mathrm{HPO}_{4}, 20 \mathrm{~g} / \mathrm{L}$ glucose, $10 \%$ fetal bovine serum [FBS]) overnight anaerobically at $37^{\circ} \mathrm{C}$ without shaking and diluted $1: 10$ or $1: 100$ just prior to inoculation. $N$. gonorrhoeae strain 23482 is a clinical isolate from male urethral source obtained from the Minnesota Department of Health. Bacteria from a freshly streaked modified Thayer-martin (MTM) agar plate (VWR, 90006-270) were scrapped into $1 \mathrm{ml}$ of media followed by vortexing and diluting 1:100 for immediate use as $N$. gonorrhoeae inocula. Anaerobic conditions $\left(<1.0 \% \mathrm{O}_{2},>13 \%\right.$ $\mathrm{CO}_{2}$ ) for relevant experiments were achieved using the GasPak system (BD Biosciences, 260672, 260001). A spiral plater (Biotek, Microbiology International) was used for enumeration of CFUs. Lactobacillus spp. and G. vaginalis were plated on tryptic soy agar containing $5 \%$ sheep's blood (Fisher, B11947) and N. gonorrhoeae was plated on MTM agar.

\section{Ex vivo porcine vaginal mucosa}

Specimens of normal porcine vaginal mucosa (PVM) are excised from mature (6 months), animals at slaughter in the University of Minnesota Andrew Boss Laboratory of Meat Science and transported to the laboratory in antibiotic-free RPMI 1640 (Gibco) with $10 \%$ fetal calf serum. The vaginal tissue is a by-product of the slaughter of animals for human consumption and therefore is Institutional Animal Care and Use Committee (IACUC) exempt. Tissue was utilized within $3 \mathrm{~h}$ of excision. Explants of uniform size were obtained using a $5 \mathrm{~mm}$ biopsy punch and excess muscle was trimmed away with a scalpel. Explants were sterilized via $1 \mathrm{~min}$ incubation with $10 \%$ povidone-iodine (PI) (Alfa Aesar, 45782). The explants were rinsed once with $10 \mathrm{ml}$ standard sampling solution ( $3 \mathrm{mM} \mathrm{KH} \mathrm{KH}_{4}, 71 \mathrm{mM} \mathrm{Na} \mathrm{PPO}_{4}, 0.1 \%$ Triton X-100, $3 \%$ Tween $80,3 \mathrm{~g} / \mathrm{L}$ lecithin, $4 \mathrm{mM}$ $\left.\mathrm{Na}_{2} \mathrm{~S}_{2} \mathrm{O}_{3} \cdot 5 \mathrm{H}_{2} \mathrm{O}\right)$ to neutralize PI and three times with $10 \mathrm{ml}$ RPMI and placed mucosal side up on a PET track-etched $0.4 \mathrm{~mm}$ cell culture insert (Fisher, 0877115) in 6-well plates containing $1 \mathrm{ml}$ of indicated media below inserts. The mucosal surface was continually exposed to the aerobic or anaerobic environment.

For bacterial colonization of PVM, explants were inoculated with $\sim 10^{4} \mathrm{CFU} /$ explant. Lactobacillus spp. and G. vaginalis were incubated anaerobically while $N$. gonorrhoeae was incubated aerobically on explants for indicated times at $37{ }^{\circ} \mathrm{C}$. Explants were vortexed in $250 \mu \mathrm{l}$ PBS for $4 \mathrm{~min}$ at max speed to release bacteria for analysis of CFU/explant and CFU/ml.

To determine the effects of various acids on bacterial growth: lactic acid (Sigma, 69785) was used at $15 \mathrm{mM}$

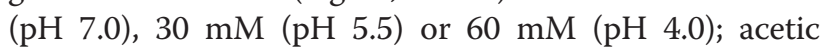
acid was used at $20 \mathrm{mM}$ (pH 7.0), $100 \mathrm{mM}$ (pH 5.5) or $750 \mathrm{mM}$ (pH 4.0); hydrochloric acid $(\mathrm{HCl})$ was used at $5 \mathrm{mM}$ (pH 7.0), $15 \mathrm{mM} \mathrm{pH} \mathrm{5.5)} \mathrm{or} 40 \mathrm{mM}$ (pH 4.0). To achieve RPMI at $\mathrm{pH} 7.0$ for each acid, the acids were added to RPMI at the indicated molarity and the solution $\mathrm{pH}$-adjusted with $\mathrm{NaOH}$. Explants were inoculated with $\sim 10^{4} \mathrm{CFU} /$ explant and incubated for $48 \mathrm{~h}$ at $37{ }^{\circ} \mathrm{C}$ over indicated media. L. crispatus and G. vaginalis were incubated anaerobically while $N$. gonorrhoeae were incubated aerobically. Explants were then processed as above.

For co-colonization experiments, overnight cultures of L. crispatus $(\mathrm{pH} 4.0)$ were sterile filtered $(0.45 \mu \mathrm{m})$ to produce conditioned media $(\mathrm{CM})$. $\mathrm{CM}$ was diluted by $\sim 1 / 2$ with unbuffered RPMI 1640 (GIBCO, 11875-093) to reach $\mathrm{pH} 6.0$ - 5.5. As indicated in figures, either RPMI + CM, RPMI + lactic acid or unbuffered RPMI was used for each experiment. Explants were washed for $30 \mathrm{~min}$ in relevant media and placed in transwells over $1 \mathrm{ml}$ of corresponding media. Explants were inoculated with $\sim 10^{4}$ L. crispatus CFU/explant and incubated anaerobically for $48 \mathrm{~h}$ at $37^{\circ} \mathrm{C}$. Explants were then inoculated with $\sim 10^{4} \mathrm{G}$. vaginalis or $N$. gonorrhoeae CFU/explant and incubated anaerobically or aerobically, respectively, for $48 \mathrm{~h}$. Explants were processed as above for CFU analysis. The $\mathrm{pH}$ of the underlying media was recorded at $0 \mathrm{~h}$, $48 \mathrm{~h}$ and $96 \mathrm{~h}$.

\section{Analysis of lactic acid production}

The media below transwells used in the L. crispatus/G. vaginalis co-colonization experiments described above were collected at the end of the experiment ( $96 \mathrm{~h}$ ) and stored at $4{ }^{\circ} \mathrm{C}$ for further analysis. Levels of $\mathrm{D}$ - and L- lactic acid in the media were assessed using a lactate quantification assay kit according to the manufacturer's instructions (BioAssay Systems, EFDLC-100 and EFLLC-100).

\section{Biofilm microscopy}

Uninfected and PVM explants colonized with various bacterial strains and incubated for $24-96 \mathrm{~h}$ at $37{ }^{\circ} \mathrm{C}$ were stained using the LIVE/DEAD Biofilm Viability kit (Invitrogen, L10316) according to instructions. Explants 
were washed three times with $1 \mathrm{ml} /$ well in Hank's balanced salt solution (Life Technologies, 14185052) and transferred to glass slides. A $1 \mathrm{~mm}$ spacer (Electron Microscopy Sciences, 70327-10) with a glass coverslip was placed over the explants. The epithelial surface of the explants was imaged with a Nikon Ni-E confocal microscope using a $60 \mathrm{X}$ oil immersion objective. Images were captured and processed using the Nikon NIS Elements software. Imaging was performed at the University Imaging Centers at the University of Minnesota.

\section{Statistical analysis}

All data shown are representative of at least 3 independent experiments with at least 3 replicates $(N \geq 3, n \geq 3)$ unless otherwise noted. Graphs were produced and statistical analysis performed using the Prism software (GraphPad). Statistical differences were determined using either OneWay ANOVA (with Dunnett's multiple comparison test) or (when only two conditions were being compared) Student's $t$-test.

\section{Availability of supporting data}

The data set(s) supporting the results of this article is (are) included within the article (and its additional file(s)).

\section{Abbreviations}

BV: Bacterial vaginosis; STI: Sexually transmitted infection; PVM: Porcine vaginal mucosa; PID: Pelvic inflammatory disease; $\mathrm{H}_{2} \mathrm{O}_{2}$ : Hydrogen peroxide; $\mathrm{HCl}$ : Hydrochloric acid; CM: Conditioned media; CDC: Cholesterol dependent cytolysin; VLY: Vaginolysin.

\section{Competing interests}

The authors have no competing interests.

\section{Authors' contributions}

$L B, V E$, JR and MP conceived and designed the experiments. $L B$ performed the experiments. $L B$ analyzed the data. $L B, V E, J R$, and MP contributed to data interpretation. $L B, V E, J R$, and MP contributed materials and reagents. $L B$ drafted the manuscript. All authors read and approved of the final manuscript.

\section{Acknowledgements}

We would like to thank Dr. Michele Anderson for helpful discussions, Heidi Wang for technical assistance and Mark Sanders for imaging support. This work was funded with support from the Office of the Vice President for Research, University of Minnesota. The research reported in this publication was supported in part by the National Institute of Allergy and Infectious Diseases of the National Institutes of Health under award number U19AI084044. The content is solely the responsibility of the authors and does not necessarily represent the official views of the National Institutes of Health.

\section{Author details}

'Department of Experimental and Clinical Pharmacology, College of Pharmacy, University of Minnesota, 4-442 McGuire Translational Research Facility, 2001 6th St. SE, Minneapolis, MN 55455, USA. ${ }^{2}$ Institute for Genome Sciences, University of Maryland, School of Medicine, Bio Park II, 6th Floor, 801 West Baltimore St., Baltimore, MD 21201, USA.

Received: 1 September 2015 Accepted: 30 November 2015

Published online: 09 December 2015

\section{References}

1. Barrett S, Taylor C. A review on pelvic inflammatory disease. Int J STD AIDS. 2005; $16: 715-20$
2. Schwebke JR. Bacterial vaginosis: are we coming full circle? J Infect Dis. 2009:200:1633-5

3. Swidsinski A, Doerffel Y, Loening-Baucke V, Swidsinski S, Verstraelen $H$, Vaneechoutte $M$, et al. Gardnerella biofilm involves females and males and is transmitted sexually. Gynecol Obstet Inves. 2010;70:256-63.

4. Hillier SL, Krohn MA, Cassen E, Easterling TR, Rabe LK, Eschenbach DA. The role of bacterial vaginosis and vaginal bacteria in amniotic fluid infection in women in preterm labor with intact fetal membranes. Clin Infect Dis. 1995; 20 Suppl 2:S276-8.

5. Hitti J, Hillier SL, Agnew KJ, Krohn MA, Reisner DP, Eschenbach DA. Vaginal indicators of amniotic fluid infection in preterm labor. Obstet Gynecol. 2001; 97:211-9.

6. Sewankambo N, Gray RH, Wawer MJ, Paxton L, McNairn D, Wabwire-Mangen F, et al. HIV-1 infection associated with abnormal vaginal flora morphology and bacterial vaginosis. Lancet. 1997;350:546-50.

7. Watts DH, Krohn MA, Hillier SL, Eschenbach DA. Bacterial vaginosis as a risk factor for post-cesarean endometritis. Obstet Gynecol. 1990;75:52-8.

8. Wiesenfeld HC, Hillier SL, Krohn MA, Amortegui AJ, Heine RP, Landers DV, et al. Lower genital tract infection and endometritis: insight into subclinical pelvic inflammatory disease. Obstet Gynecol. 2002;100:456-63.

9. Wiesenfeld HC, Hillier SL, Krohn MA, Landers DV, Sweet RL. Bacterial vaginosis is a strong predictor of Neisseria gonorrhoeae and Chlamydia trachomatis infection. Clin Infect Dis. 2003:36:663-8.

10. Fredricks DN, Fiedler TL, Marrazzo JM. Molecular Identification of Bacteria Associated with Bacterial Vaginosis. N Engl J Med. 2005;353:1899-911.

11. Hill GB. The microbiology of bacterial vaginosis. Am J Obstet Gynecol. 1993; 169:450-4.

12. Spiegel CA. Bacterial vaginosis. Clin Microbiol Rev. 1991;4:485-502.

13. Nugent RP, Krohn MA, Hillier SL. Reliability of diagnosing bacterial vaginosis is improved by a standardized method of gram stain interpretation. J Clin Microbiol. 1991;29:297-301.

14. Kenyon $\mathrm{CR}$, Osbak K. Recent progress in understanding the epidemiology of bacterial vaginosis. Curr Opin Obstet Gyn. 2014;26:448-54.

15. Turovskiy Y, Sutyak Noll K, Chikindas ML. The aetiology of bacterial vaginosis. J Appl Microbiol. 2011;110:1105-28.

16. Antonio MA, Hawes SE, Hillier SL. The identification of vaginal Lactobacillus species and the demographic and microbiologic characteristics of women colonized by these species. J Infect Dis. 1999;180:1950-6.

17. Hillier SL, Krohn MA, Klebanoff SJ, Eschenbach DA. The relationship of hydrogen peroxide-producing lactobacilli to bacterial vaginosis and genital microflora in pregnant women. Obstet Gynecol. 1992;79:369-73.

18. Ravel J, Gajer P, Abdo Z, Schneider GM, Koenig SSK, McCulle SL, et al. Vaginal microbiome of reproductive-age women. Proc Natl Acad Sci U S A. 2011;108 Suppl 1:4680-7.

19. Sobel JD. Is there a protective role for vaginal flora? Curr Infect Dis Rep. 1999;1: 379-83.

20. Saigh JH, Sanders C, Sanders WEI. Inhibition of Neisseria gonorrhoeae by aerobic and facultatively anaerobic components of the endocervical flora: evidence for a protective effect against infection. Infect Immun. 1978;19:704-10.

21. Aroutcheva A, Gariti D, Simon M, Shott S, Faro J, Simoes JA, et al. Defense factors of vaginal Lactobacilli. Am J Obstet Gynecol. 2001;185:375-9.

22. Atassi F, Brassart D, Grob P, Graf F, Servin AL. Lactobacillus strains isolated from the vaginal microbiota of healthy women inhibit Prevotella bivia and Gardnerella vaginalis in coculture and cell culture. FEMS Immunol Med Mic. 2006;48:424-32.

23. Dover SE, Aroutcheva AA, Faro S, Chikindas ML. Natural antimicrobials and their role in vaginal health: a short review. Int J Probiotics Prebiotics. 2008;3: 219-30.

24. Eschenbach DA, Davick PR, Williams BL, Klebanoff SJ, Young-Smith K, Critchlow $\mathrm{CM}$, et al. Prevalence of hydrogen peroxide-producing Lactobacillus species in normal women and women with bacterial vaginosis. J Clin Microbiol. 1989;27: 251-6.

25. Graver MA, Wade JJ. The role of acidification in the inhibition of Neisseria gonorrhoeae by vaginal lactobacilli during anaerobic growth. Ann Clin Microbiol Antimicrob. 2011;10:8.

26. O'Hanlon DE, Moench TR, Cone RA. In vaginal fluid, bacteria associated with bacterial vaginosis can be suppressed with lactic acid but not hydrogen peroxide. BMC Infect Dis. 2011;11:200

27. St Amant DC, Valentin-Bon IE, Jerse AE. Inhibition of Neisseria gonorrhoeae by Lactobacillus species that are commonly isolated from the female genital tract. Infect Immun. 2002;70:7169-71. 
28. Zheng HY, Alcorn TM, Cohen MS. Effects of H2O2-producing lactobacilli on Neisseria gonorrhoeae growth and catalase activity. J Infect Dis. 1994;170:1209-15.

29. Barfod KK, Roggenbuck M, Hansen LH, Schjørring S, Larsen ST, Sørensen SJ, et al. The murine lung microbiome in relation to the intestinal and vaginal bacterial communities. BMC Microbiol. 2013;13:303.

30. Gilbert NM, Lewis WG, Lewis AL. Clinical features of bacterial vaginosis in a murine model of vaginal infection with Gardnerella vaginalis. PLoS One. 2013;8:e59539.

31. Hymes SR, Randis TM, Sun TY, Ratner AJ. DNase inhibits Gardnerella vaginalis biofilms in vitro and in vivo. J Infect Dis. 2013;207:1491-7.

32. Jerse AE, Wu H, Packiam M, Vonck RA, Begum AA, Garvin LE. Estradiol-treated female mice as surrogate hosts for Neisseria gonorrhoeae genital tract infections. Front Microb. 2011;2:107.

33. Spencer SE, Valentin-Bon IE, Whaley K, Jerse AE. Inhibition of Neisseria gonorrhoeae genital tract infection by leading-candidate topical microbicides in a mouse model. J Infect Dis. 2004;189:410-9.

34. Squier CA, Mantz MJ, Schlievert PM, Davis CC. Porcine vagina ex vivo as a model for studying permeability and pathogenesis in mucosa. J Pharm Sci. 2008;97:9-21.

35. Anderson MJ, Horn ME, Lin Y-C, Parks PJ, Peterson ML. Efficacy of concurrent application of chlorhexidine gluconate and povidone iodine against six nosocomial pathogens. Am J Infect Control. 2010;38:826-31.

36. Anderson MJ, Lin Y-C, Gillman AN, Parks PJ, Schlievert PM, Peterson ML. Alpha-toxin promotes Staphylococcus aureus mucosal biofilm formation. Front Cell Infect Microb. 2012;2:64.

37. Anderson MJ, Parks PJ, Peterson ML. A mucosal model to study microbial biofilm development and anti-biofilm therapeutics. J Microbiol Meth. 2013; 92:201-8.

38. Anderson MJ, Scholz MT, Parks PJ, Peterson ML. Ex vivo porcine vaginal mucosal model of infection for determining effectiveness and toxicity of antiseptics. J Appl Microbiol. 2013;115:679-88.

39. Brosnahan AJ, Schaefers MM, Amundson WH, Mantz MJ, Squier CA, Peterson ML, et al. Novel toxic shock syndrome toxin-1 amino acids required for biological activity. Biochem. 2008;47:12995-3003.

40. Brosnahan AJ, Mantz MJ, Squier CA, Peterson ML, Schlievert PM. Cytolysins augment superantigen penetration of stratified mucosa. J Immunol. 2009; 182:2364-73.

41. Davis CC, Kremer MJ, Schlievert PM, Squier CA. Penetration of toxic shock syndrome toxin-1 across porcine vaginal mucosa ex vivo: permeability characteristics, toxin distribution, and tissue damage. Am J Obstet Gynecol. 2003;189:1785-91.

42. Davis CC, Baccam M, Mantz MJ, Osborn TW, Hill DR, Squier CA. Use of porcine vaginal tissue ex-vivo to model environmental effects on vaginal mucosa to toxic shock syndrome toxin-1. Toxicol Appl Pharm. 2014;274:240-8.

43. Lin Y-C, Anderson MJ, Kohler PL, Strandberg KL, Olson ME, Horswill AR, et al. Proinflammatory exoprotein characterization of toxic shock syndrome Staphylococcus aureus. Biochem. 2011;50:7157-67.

44. Peterson ML, Ault K, Kremer MJ, Klingelhutz AJ, Davis CC, Squier CA, et al. The innate immune system is activated by stimulation of vaginal epithelial cells with Staphylococcus aureus and toxic shock syndrome toxin 1. Infect Immun. 2005;73:2164-74.

45. Schaefers MM, Breshears LM, Anderson MJ, Lin Y-C, Grill AE, Panyam J, et al. Epithelial proinflammatory response and curcumin-mediated protection from staphylococcal toxic shock syndrome toxin-1. PLoS One. 2012;7: e32813.

46. Yang $\mathrm{Q}$, Phillips $\mathrm{PL}$, Sampson EM, Progulske-Fox A, Jin S, Antonelli $\mathrm{P}$, et al. Development of a novel ex vivo porcine skin explant model for the assessment of mature bacterial biofilms. Wound Repair Regen. 2013; 21:704-14.

47. Greiner LL, Edwards JL, Shao J, Rabinak C, Entz D, Apicella MA. Biofilm formation by Neisseria gonorrhoeae. Infect Immun. 2005;73:1964-70.

48. Steichen $\mathrm{CT}$, Shao JQ, Ketterer MR, Apicella MA. Gonococcal cervicitis: a role for biofilm in pathogenesis. J Infect Dis. 2008;198:1856-61.

49. Muli FW, Struthers JK. The growth of Gardnerella vaginalis and Lactobacillus acidophilus in Sorbarod biofilms. J Med Microbiol. 1998;47:401-5.

50. Swidsinski A, Mendling W, Loening-Baucke V, Ladhoff A, Swidsinski S, Hale LP, et al. Adherent biofilms in bacterial vaginosis. Obstet Gynecol. 2005;106:1013-23.

51. Swidsinski A, Mendling W, Loening-Baucke V, Swidsinski S, Dörffel Y, Scholze J, et al. An adherent Gardnerella vaginalis biofilm persists on the vaginal epithelium after standard therapy with oral metronidazole. Am J Obstet Gynecol. 2008;198: 97.e1-97.e6.
52. Swidsinski A, Dörffel Y, Loening-Baucke V, Schilling J, Mendling W. Response of Gardnerella vaginalis biofilm to 5 days of moxifloxacin treatment. FEMS Immunol Med Mic. 2010;61:41-6.

53. Al-Mushrif S, Eley A, Jones BM. Inhibition of chemotaxis by organic acids from anaerobes may prevent a purulent response in bacterial vaginosis. J Med Microbiol. 2000:49:1023-30.

54. Chaudry AN, Travers PJ, Yuenger J, Colletta L, Evans P, Zenilman JM, et al. Analysis of vaginal acetic acid in patients undergoing treatment for bacterial vaginosis. J Clin Microbiol. 2004;42:5170-5.

55. Mirmonsef P, Gilbert D, Zariffard MR, Hamaker BR, Kaur A, Landay AL, et al. The Effects of Commensal Bacteria on Innate Immune Responses in the Female Genital Tract. Am J Reprod Immunol. 2010;65:190-5.

56. Stanek R, Gain RE, Glover DD, Larsen B. High performance ion exclusion chromatographic characterization of the vaginal organic acids in women with bacterial vaginosis. Biomed Chromatogr. 1992;6:231-5.

57. Klebanoff SJ, Hillier SL, Eschenbach DA, Waltersdorph AM. Control of the microbial flora of the vagina by H2O2-generating lactobacilli. J Infect Dis. 1991;164:94-100.

58. Edwards JL, Shao JQ, Ault KA, Apicella MA. Neisseria gonorrhoeae elicits membrane ruffling and cytoskeletal rearrangements upon infection of primary human endocervical and ectocervical cells. Infect Immun. 2000;68:5354-63.

59. Edwards JL, Brown EJ, Ault KA, Apicella MA. The role of complement receptor 3 (CR3) in Neisseria gonorrhoeae infection of human cervical epithelia. Cell Microbiol. 2001;3:611-22.

60. Edwards JL, Butler EK. The pathobiology of Neisseria gonorrhoeae lower female genital tract infection. Front Microb. 2011;2:102.

61. Evans BA. Ultrastructural study of cervical gonorrhea. J Infect Dis. 1977;136: 248-55.

62. Aleshkin VA, Voropaeva EA, Shenderov BA. Vaginal microbiota in healthy women and patients with bacterial vaginosis and nonspecific vaginitis. Microb Ecol Health D. 2006;18:71-4.

63. Antonio MAD, Meyn LA, Murray PJ, Busse B, Hillier SL. Vaginal colonization by probiotic Lactobacillus crispatus CTV-05 is decreased by sexual activity and endogenous Lactobacilli. J Infect Dis. 2009;199:1506-13.

64. Sheiness D, Dix K, Watanabe S, Hillier SL. High levels of Gardnerella vaginalis detected with an oligonucleotide probe combined with elevated $\mathrm{pH}$ as a diagnostic indicator of bacterial vaginosis. J Clin Microbiol. 1992;30:642-8.

65. Young $H$, Sarafian SK, Harris AB, McMillan A. Non-cultural detection of Neisseria gonorrhoeae in cervical and vaginal washings. J Med Microbiol. 1983:16:183-91.

66. Alves P, Castro J, Sousa C, Cereija TB, Cerca N. Gardnerella vaginalis outcompetes 29 other bacterial species isolated from patients with bacterial vaginosis, using in an in vitro biofilm formation model. J Infect Dis. 2014;210:593-6.

67. Patterson JL, Stull-Lane A, Girerd PH, Jefferson KK. Analysis of adherence, biofilm formation and cytotoxicity suggests a greater virulence potential of Gardnerella vaginalis relative to other bacterial-vaginosis-associated anaerobes. Microbiology. 2010;156:392-9.

68. Harwich MD, Alves JM, Buck GA, Strauss JF, Patterson JL, Oki AT, et al. Drawing the line between commensal and pathogenic Gardnerella vaginalis through genome analysis and virulence studies. BMC Genomics. 2010;11:375.

69. Gelber SE, Aguilar JL, Lewis KLT, Ratner AJ. Functional and phylogenetic characterization of Vaginolysin, the human-specific cytolysin from Gardnerella vaginalis. J Bacteriol. 2008;190:3896-903.

70. Rottini G, Dobrina A, Forgiarini O, Nardon E, Amirante GA, Patriarca P. Identification and partial characterization of a cytolytic toxin produced by Gardnerella vaginalis. Infect Immun. 1990;58:3751-8.

71. Hooven TA, Randis TM, Hymes SR, Rampersaud R, Ratner AJ. Retrocyclin inhibits Gardnerella vaginalis biofilm formation and toxin activity. J Antimicrob Chemother. 2012;67:2870-2.

72. Blanchette-Cain K, Hinojosa CA, Akula Suresh Babu R, Lizcano A, Gonzalez-Juarbe N, Munoz-Almagro C, et al. Streptococcus pneumoniae Biofilm Formation is Strain Dependent, Multifactorial, and Associated with Reduced Invasiveness and Immunoreactivity during Colonization. mBio. 2013;4:e00745-13.

73. Ahmed A, Earl J, Retchless A, Hillier SL, Rabe LK, Cherpes TL, et al. Comparative genomic analyses of 17 clinical isolates of Gardnerella vaginalis provide evidence of multiple genetically isolated clades consistent with subspeciation into genovars. J Bacteriol. 2012;194:3922-37.

74. Spurbeck RR, Arvidson CG. Lactobacilli at the front line of defense against vaginally acquired infections. Future Microbiol. 2011;6:567-82.

75. Witkin SS, Mendes-Soares H, Linhares IM, Jayaram A, Ledger WJ, Forney LJ. Influence of vaginal bacteria and D- and L-lactic acid isomers on vaginal 
extracellular matrix metalloproteinase inducer: implications for protection against upper genital tract infections. mBio. 2013;4:e00460-13.

76. O'Hanlon DE, Lanier BR, Moench TR, Cone RA. Cervicovaginal fluid and semen block the microbicidal activity of hydrogen peroxide produced by vaginal lactobacilli. BMC Infect Dis. 2010;10:120.

77. Anderson MJ, David ML, Scholz M, Bull SJ, Morse D, Hulse-Stevens M, et al. Efficacy of Skin and Nasal Povidone-lodine Preparation against MupirocinResistant Methicillin-Resistant Staphylococcus aureus and S. aureus within the Anterior Nares. Antimicrob Agents Chemother. 2015;59:2765-73.

78. Parma M, Stella Vanni V, Bertini M, Candiani M. Probiotics in the prevention of recurrences of bacterial vaginosis. Altern Ther Health M. 2014;20:52-7.

79. Gajer P, Brotman RM, Bai G, Sakamoto J, Schutte UME, Zhong X, et al. Temporal Dynamics of the Human Vaginal Microbiota. Sci Transl Med. 2012; 4:132ra52-132ra52.

80. Ravel J, Brotman RM, Gajer P, Ma B, Nandy M, Fadrosh DW, et al. Daily temporal dynamics of vaginal microbiota before, during and after episodes of bacterial vaginosis. Microbiome. 2013;1:29.

\section{Submit your next manuscript to BioMed Central} and we will help you at every step:

- We accept pre-submission inquiries

- Our selector tool helps you to find the most relevant journal

- We provide round the clock customer support

- Convenient online submission

- Thorough peer review

- Inclusion in PubMed and all major indexing services

- Maximum visibility for your research 